\title{
Impact of COVID-19 Pandemic on Physical Activity and Spinal Pain in a Group of Apparently Healthy Egyptians: A Cross Sectional Study
}

\author{
AHMED KOHEIL, M.D.*; DALIA DORGHAM, M.D.**; WAEL NAZIM, M.D.* and DOAA H.S. ATTIA, M.D.** \\ The Department of Neurosurgery, Faculty of Medicine, Beni Sueif University* and Reumatology and Rehabilitation Department, \\ Faculty of Medicine, Cairo University**
}

\begin{abstract}
Background: Spinal pain is a frequent health problem. Sedentary lifestyle and lack of physical activity PA had been widely pointed out as a risk factor for LBP. Since the end of 2019, the world has been facing the COVID-19 pandemic, this resulted in change of lifestyle and PA performed by lots of people.

Aim of Study: To detect change in PA before and after COVID-19 pandemic and its relation to LBP, cervical pain, nonspecific bodily pains or fatigue.

Patients and Methods: The current study included 146 apparently healthy participants whom were asked to answer the validated Arabic version of International Physical Assessment Questionnaire IPAQ to assess PA before and after COVID-19 pandemic. Participants also answered questions to assess new onset of symptoms and/or increased symptoms in terms of LBP, nonspecific bodily pains or fatigue.
\end{abstract}

Results: Participants were divided into two groups based on the presence of spinal pain, joint pains, bodily pains and fatigue: Worsened group who developed the symptom after COVID-19 pandemic or had worsening of an old symptom after the pandemic, and stable group who had no symptoms after the pandemic or had an old symptom that did not increase after the pandemic. There was significant change in high intensity PA after the pandemic $(p<0.001)$. Participants who experienced spinal pains had significantly practiced walking $(p=0.002)$ and moderate intensity activities $(p=0.038)$ before the pandemic. There was significant correlation between performing high intensity PA during COVID-19 pandemic and stable spinal pain, nonspecific bodily pains and fatigue ( $p=0.021, p=0.025, p=0.046)$ respectively. Individuals who experienced worsening in spinal pains, nonspecific bodily pains or fatigue had significant change in moderate intensity activity days $(p=0.049)$ and duration $(p=0.022)$ after the pandemic.

Conclusion: The changes in moderate intensity PA is related to spinal pain, nonspecific body pain and fatigue.

Key Words: Physical activity - COVID-19-Sport - LBP.

Correspondence to: Dr. Ahmed Koheil,

E-Mail: akoheil@med.bsu.edu.eg

\section{Introduction}

LOW back pain (LBP)is a very common health problem; it is considered the second most common type of pain after headache [1,2]. It is believed that two thirds of the population by the age of 40 years would have experienced at least one episode of LBP and $60 \%$ of them would suffer from recurrent LBP during the same year [3-5]. Being one of the most common health complaints in many countries, LBP leads to numerous sick leaves with subsequent economic burden [6-8] .

Many researchers investigated the risk factors associated with LBP and tried to determine its relation to lifestyle, level of physical activity (PA), habitual positions during work, working hours, metabolic syndrome, smoking, excessive alcohol consumption and, even, nutrition [9-19]

According to the World Health Organization (WHO), physical activity is defined as any bodily movement that is produced by skeletal muscles and requires energy expenditure above the basal metabolic rate. PA and sports involve a wide range of low to intense activity such as: Brisk walking, swimming, cycling and competitive sports. Specialized facilities and clubs are often involved in many kinds of activities and sports [20]. On the other side, sedentary lifestyle is defined as prolonged sitting at work in addition to leisure time; or an energy expenditure less than 600 metabolic equivalent of task (MET) minute per week [21].

Sedentary lifestyle has long been considered risk factor for non-specific LBP [10-12] . An association between prolonged sitting during work time and LBP was reported by several studies [13-15] 
Another study involving adolescents reported an association between LBP and prolonged sitting in girls [19]. Other interventional studies revealed that activity based-work environment was associated with a half reduction of LBP frequency compared with the baseline inactive work environment $[13,17]$

World Health Organization declared coronavirus disease-2019 (COVID-19), caused by the severe acute respiratory syndrome-coronavirus 2 (SARSCoV2), a worldwide pandemic. Until the development of an effective vaccine against this potentially life-threatening respiratory virus, the $\mathrm{WHO}$ has been providing regular recommendations to avoid crowdedness, and to adopt the policy of social distancing. The consequences of such recommendations included the lockdown of clubs, many sport facilities and gymnastic rooms; working from home whenever possible; and the avoidance of any unnecessary outdoor activities [22]

The study aimed to detect the changes in the level of PA of individuals as a result of COVID19 pandemic, and to find out the association between those changes and any worsening or new onset of neck/back pain.

\section{Patients and Methods}

The current study included apparently healthy volunteers aged 18 to 55 years who were relatives of patients attending the Rheumatology and Rehabilitation clinic, or Neurosurgery clinic in the institutes where the researchers are working; Rheumatology and Rehabilitation outpatient clinic, Faculty of Medicine, Cairo University or Neurosurgery Outpatient Clinic, Faculty of Medicine, BeniSuef University. Participants were recruitedin the period between first of June and first of September 2020.

Participants through the written form gave a written informed consent. The Google form contained a section about approving the participation in a scientific research, submitting the online form after finishing it was the substitute to the written conscent.

Participants were recruited in the period between first of June and first of September 2020. Participants were invited to fill out a Google form available online or an identical written copy which takes 5-10 minutes to answer. The online form could be accessed through https://docs.google.com/ forms/d/ 1 QwMfLDxJdfj xUO6zdxuLJEYn7pt6i VYyGTvG5XMf1E/edit?usp=drive web. In addition to demographic features, the form included answering the validated Arabic version of the
International Physical Assessment QuestionnaireShort Form (IPAQ-SF) [23]. The participants were asked to answer a section to assess PA during a regular week before COVID-19 pandemic and another section to assess PA in the past 7 days during the COVID-19 pandemic. Other questions regarding worsening of an old or development of a new onset LBP and/or neck pain following the pandemic were to be answered as well. Individuals with an established rheumatologic disease as rheumatoid arthritis or fibromyalgia, and those with a recent history of bone or joint surgery were excluded.

Statistical analysis: Categorical variables were described in terms of frequencies and percentages. Numerical variables were described in terms of median and interquartile range (IQR) or mean \pm SD according to the normality of data. Comparisons were performed using the chi-square test for categorical data and the unpaired-samples $t$-test for numerical data. A two-tailed probability value ( $p$ value) was used; and a $p$-value $<0.05$ was considered statistically significant. For the comparison of paired categorical data, McNemarBowker test was used; post hoc analysis was performed with the $p$-value adjusted at 0.006 after Bonferroni correction. All statistical calculations were performed using SPSS (Statistical Package for the Social Science; SPSS, Inc., Chicago, IL, USA) version 21 for Microsoft Windows.

Sample size calculation: Power analysis was performed on the primary outcome for independent samples. When a pilot sample of 25 individuals was considered, the total METs before and after COVID-19 pandemic were $3692.1 \pm 2507.6$ and $1162.9 \pm 993.1$ in persons with worsened and stable neck/back pain, respectively. For a power of 0.80 and an alpha error of 0.05 , a minimum sample size of 20 persons was calculated.

\section{Results}

The current study included 146 participants, $85(58.2 \%)$ females and 61 (41.8\%) males. Age ranged from 18 to 55 years with a median of $35.3 \pm$ 9.7 years. Body mass index ranged from 21.3 to 35.7 with a median of $26.9 \pm 5 \mathrm{~kg} / \mathrm{m}^{2}$. Chronic diseases controlled under medical treatment were reported in 19 participants; hypothyroidism in 8 $(5.4 \%)$, systemic hypertension in $6(4.1 \%)$, diabetes mellites in $3(2 \%)$ and bronchial asthma in $2(1.3 \%)$ participants.

Regarding work; 38 (26\%) were working from home due to the pandemic, 57 (39\%) were working at office as usual, $12(8.2 \%)$ were students, $5(3.4 \%)$ 
quit or got dismissed from work due to the pandemic and 34 (23.3\%) were not employed even before the pandemic.

Concerning weight changes; $81(55.5 \%)$ participants experienced weight gain while $24(16.4 \%)$ subjects lost weight during the pandemic and 41 (28.1\%) kept stable body weight. Nineteen out of $33(57.6 \%)$ individuals using non-steroidal antiinflammatory drugs before COVID-19 pandemic stopped treatment after the epidemic due to claims that Ibuprofen intake during COVID-19 infection worsens prognosis. Seventeen out of $20(85 \%)$ individuals receiving physiotherapy before COVID19 pandemic stopped the sessions after the pandemic.

Participants were divided into two groups based on the presence of neck/back pain: A worsened group who developed a new onset or had worsening of an old symptom after COVID-19 pandemic, and a stable group who had no symptoms after the pandemic or had an old symptom that did not increase after the pandemic.

Table (1) shows the changes that the study cohort had concerning their levels of physical activity after COVID-19 pandemic. Post hoc analysis of the comparison revealed a significantly lower frequency of high intensity physical activity level after COVID-19 pandemic; and this difference persisted even after Bonferroni correction $(p<0.001)$.

Table (1): The comparison between the levels of physical activities of the study cohort before and during COVID-19 pandemic.

\begin{tabular}{lllll}
\hline Before & \multicolumn{1}{c}{ During } \\
$(\mathrm{n}=35)$ & $\begin{array}{c}\text { Moderate } \\
(\mathrm{n}=49)\end{array}$ & $\begin{array}{c}\text { High } \\
(\mathrm{n}=62)\end{array}$ & $\begin{array}{c}p- \\
\text { value }\end{array}$ \\
\hline Low $(\mathrm{n}, \%)$ & $26(74.3)$ & $20(40.8)$ & $21(33.9)$ & $<0.001 *$ \\
Moderate (n,\%) & $7(20)$ & $27(55.1)$ & $27(43.5)$ & \\
High (n,\%) & $2(5.7)$ & $2(4.1)$ & $14(22.6) \#$ & \\
\hline
\end{tabular}

McNemar-Bowker test was used.

${ }^{*} p$-value $<0.05$ is considered statistically significant.

\#Post hoc analysis revealed significantly lower frequency of high

level of physical activity during COVID-19 pandemic even after Bonferroni correction.

Table (2) demonstrates the physical activity status prior to COVID-19 pandemic in the two groups. Participants who suffered worsening of neck/back pain had a higher frequency of practicing moderate intensity PA, and a longer duration of performing moderate activity and walking before the pandemic.
Table (2): Physical activity status prior to COVID-19 pandemic in the different groups.

\begin{tabular}{llll}
\hline & \multicolumn{2}{c}{ Neck/back pain } & $\begin{array}{c}p- \\
\text { value }\end{array}$ \\
\cline { 2 - 3 } & $\begin{array}{c}\text { Worsened } \\
(\mathrm{n}=67)\end{array}$ & $\begin{array}{c}\text { Stable } \\
(\mathrm{n}=79)\end{array}$ & \\
\hline $\begin{array}{c}\text { High intensity activity } \\
\text { frequency (days) }\end{array}$ & $3(1-4)$ & $2(0-5)$ & 0.388 \\
$\begin{array}{c}\text { High intensity activity } \\
\text { duration (minutes) }\end{array}$ & $60(0-60)$ & $60(0-60)$ & 0.495 \\
$\begin{array}{c}\text { Moderate intensity } \\
\text { activity frequency } \\
\text { (days) }\end{array}$ & $4(2-6)$ & $2(0-5)$ & $0.002^{*}$ \\
$\begin{array}{c}\text { Moderate intensity } \\
\text { activity duration } \\
\text { (minutes) }\end{array}$ & $60(30-70)$ & $20(0-60)$ & $0.038^{*}$ \\
$\begin{array}{c}\text { Walking activity } \\
\text { frequency (days) }\end{array}$ & $5(3-7)$ & $4(0-6)$ & 0.079 \\
$\begin{array}{c}\text { Walking activity } \\
\text { duration (minutes) }\end{array}$ & $30(30-60)$ & $30(0-60)$ & $0.002^{*}$ \\
\hline
\end{tabular}

- Unpaired samples $t$-test and chi square tests were used for the numerical and categorical data, respectively.

${ }^{*} p$-value $<0.05$ is considered statistically significant.

Table (3) shows the comparison between the two groups concerning the physical activity status during COVID-19 pandemic. There was no significant change between groups.

Table (3): The comparison between the different groups concerning the physical activity during COVID19 pandemic.

\begin{tabular}{|c|c|c|c|}
\hline & \multicolumn{2}{|c|}{ Neck/back pain } & \multirow{2}{*}{$\begin{array}{c}p- \\
\text { value }\end{array}$} \\
\hline & $\begin{array}{l}\text { Worsened } \\
(\mathrm{n}=67)\end{array}$ & $\begin{array}{l}\text { Stable } \\
(\mathrm{n}=79)\end{array}$ & \\
\hline $\begin{array}{l}\text { High intensity activity } \\
\text { frequency change } \\
\text { (days) }\end{array}$ & $0(0-2)$ & $0(0-2)$ & 0.141 \\
\hline $\begin{array}{l}\text { High intensity activity } \\
\text { duration change } \\
\text { (minutes) }\end{array}$ & $0(0-35)$ & $0(0-35)$ & 0.310 \\
\hline $\begin{array}{l}\text { Moderate intensity } \\
\text { activity frequency } \\
\text { change (days) }\end{array}$ & $2(0-3)$ & $1(0-3)$ & 0.495 \\
\hline $\begin{array}{l}\text { Moderate intensity } \\
\text { activity duration } \\
\text { change (minutes) }\end{array}$ & $30(0-60)$ & $15(0-35)$ & 0.126 \\
\hline $\begin{array}{l}\text { Walking activity } \\
\text { frequency change } \\
\text { (days) }\end{array}$ & $3(1.5-7)$ & $3(0-5)$ & 0.209 \\
\hline $\begin{array}{l}\text { Walking activity } \\
\text { duration change } \\
\text { (minutes) }\end{array}$ & $30(12.5-45)$ & $20(0-52.5)$ & 0.323 \\
\hline
\end{tabular}

-Unpaired samples $t$-test was used and chi square tests were used for the numerical and categorical data, respectively.

${ }^{*} p$-value $<0.05$ is considered statistically significant. 
Table (4) shows the comparison between the two groups concerning the change of PA after COVID-19 pandemic. The worsened group concerning the neck/back pain had a significantly greater decrease of moderate intensity PA frequency $(p=0.049)$.

Table (4): The comparison between the different groups concerning the change of physical activity before and after COVID-19 pandemic.

\begin{tabular}{|c|c|c|c|}
\hline & \multicolumn{2}{|c|}{ Neck/back pain } & \multirow{2}{*}{$\begin{array}{c}p- \\
\text { value }\end{array}$} \\
\hline & $\begin{array}{l}\text { Worsened } \\
\quad(n=67)\end{array}$ & $\begin{array}{l}\text { Stable } \\
(n=79)\end{array}$ & \\
\hline $\begin{array}{l}\text { High intensity activity } \\
\text { frequency change } \\
\text { (days) }\end{array}$ & $57.1(0-100)$ & $0(0-100)$ & 0.222 \\
\hline $\begin{array}{l}\text { High intensity activity } \\
\text { duration change } \\
\text { (minutes) }\end{array}$ & $50(0-100)$ & $0(0-100)$ & 0.075 \\
\hline $\begin{array}{l}\text { Moderate intensity } \\
\text { activity frequency } \\
\text { change (days) }\end{array}$ & $40(0-92.9)$ & $0(0-57.14)$ & $0.049 *$ \\
\hline $\begin{array}{l}\text { Moderate intensity } \\
\text { activity duration } \\
\text { change (minutes) }\end{array}$ & $50(0-91.7)$ & $0(0-50)$ & 0.100 \\
\hline $\begin{array}{l}\text { Walking activity } \\
\text { frequency change } \\
\text { (days) }\end{array}$ & $0(0-50)$ & $0(0-50)$ & 0.081 \\
\hline $\begin{array}{l}\text { Walking activity } \\
\text { duration change } \\
\text { (minutes) }\end{array}$ & $33.3(0-55.6)$ & $0(0-50)$ & 0.836 \\
\hline
\end{tabular}

-Unpaired samples $t$-test was used.

$* p$-value $<0.05$ is considered statistically significant.

\section{Discussion}

The worldwide lockdown of sport facilities, swimming pools and sport clubs during COVID19 pandemic forcibly decreased PA of many people; these circumstances represented a unique opportunity to study how much decreasing PA in healthy individuals contributes to musculoskeletal complaints. Very few of the earlier studies on PA and LBP and/or cervical pain studied the same individuals during active versus sedentary periods of their lives. This study also highlighted the indirectlongterm consequences of COVID-19 pandemic on musculoskeletal health.

The comparison between the levels of PA of all participants before and during COVID-19 pandemic showed a significant reduction of the high intensity PA after the pandemic. High intensity PA examples mentioned in the Arabic version of the IPAQ-SF include carrying heavy weights, running at high speed, cycling at high speed, swimming and basketball playing [23]; all these activities were expected to be difficult to practice indoors during the pandemic.

When the study's results were interpreted, the following observation came to light: The worsened group of spinal pain was more active prior to the pandemic and they had a greater reduction in their PA during the pandemic. The more sedentary group before the pandemic had no significant changes of their PA during the pandemic, and thus did not suffer significant worsening of their musculoskeletal heath. In other words, sudden reduction in PA level can lead to LBP and cervical pain.

The results of the current study come in concordance with many investigators reporting that sedentary life is associated with spinal pain [10$15,19]$, and with others stating that moderate intensity PA ,as moderate speed cycling and brisk walking, is protective against LBP and can be safely practiced in LBP patients after finishing their treatment as a part of their rehabilitation program. Hence, practicing moderate to intense PA three to five times per week has been proposed as a part of the rehabilitation program recommended for LBP patients [24-27]. Furthermore, LBP patients are advised to regularly engage into everyday activities to maintain valuable health benefits of the moderate to intense PA [28].

Few studies disagreed with the current study and stated that LBP severity at baseline but not physical inactivity determines future LBP attacks [29]. Also, an older study of sedentary life as a risk factor of LBP revealed that sedentary life, per se, is not a risk factor for LBP [30]. Those findings were disapproved by other recent studies which supported the association between sedentary life and LBP $[15,19,28,31]$.

Regular PA is also reported to improve symptoms related to unexplained fatigue and quality of life [32]. Moreover, the influence of physical exercises on improvement of fatigue was supported by randomized controlled trials $[33,34]$.

Lack of PA is believed to be associated with decreased muscle bulk and strength [35]; improper hydration of the intervertebral discs [36], increased intradiscal load [37] and decreased metabolic exchange [38]. Another suggested mechanism explainingimprovement of musculoskeletal pain by PA involvesthe enhanced expression of endorphins, enkephalins and serotonin by exercise which in turn improves physical pain and psychological wellbeing [39]. The beneficial effect of PA on musculoskeletal health and emotional state is fur- 
ther supported by $b$ the usefulness of exercises in patients with fibromyalgia [40].

The strength point of the study includesits longitudinal design to address the impact of unintentional reduction of PA on musculoskeletal health; other studies were either cross sectional without a clear delineation of the causal effect relationship between PA and sedentary life or interventional studies addressing the effect of exercise programs on sedentary persons with LBP. The current study used a validated questionnaire, IPAQ-SF Arabic version, to assess PA status before and after the pandemic. The weakness point of the study includes the retrospective recall of PA statebefore COVID19 pandemic; however, the intentional decrement of the physical status of the participant, from active to inactive state, was not ethical to be tested in a study.

Conclusion: COVID-19 pandemic resulted in lifestyle changes including jobs, level of activity and recreational sports. This study detected a significant reduction in high intensity activity as swimming and group sports. Persons who are physically active are more prone to musculoskeletal complaints when they reduce their PA compared to those who have sedentary life. Hence, physically active subjects should be advised to continue their level of PA in order to maintain the benefits of PA and avoid deconditioning. Thus, our study emphasizes the importance of adherence to PA program in order to maintain their expected benefits. In other words, one may say that practicing moderate intensity PA and walking were protective against spinal pains. Fatigue and bodily painneed to be further studied in light of PA, quality of life, stress, anxiety and depression.

Disclosure: All authors declare no conflict of interests.

Funding: No funding was received by authors of this study.

Author contribution: All authors shared equally in conception and design of the study, collecting and revising data, ensuring quality and integrity and final approval of the submitted manuscript. All authors read and agree the final version of the manuscript.

\section{References}

1- KRISMER M. and VAN TULDER M.: Low Back Pain Group of the Bone and Joint Strategies for Europe Project. Strategies for prevention and management of musculoskeletal conditions: Low back pain (non-specific). Best Practice \& Research Clinical Rheumatology, 21 (1): 77-91, 2007.
2- RICCI J.A., STEWART W.F., CHEE E., LEOTTA C., FOLEY K. and HOCHBERG M.C.: Back pain exacerbations and lost productive time costs in United States workers. Spine, 31: 3052-60, 2006.

3- HOY D., MARCH L., BROOKS P., BLYTH F., WOOLF A., BAIN C., et al.: The global burden of low back pain: Estimates from the Global Burden of Disease 2010 study. Annals of the Rheumatic Diseases, 73 (6): 968-74, 2014.

4- CITKO A., GÓRSKI S., MARCINOWICZ L. and GÓRSKA A.: Analysis of risk factors of recurring nonspecific low back pain with particular emphasis on "new" predictive factors. Family Medicine and Primary Care Review, 19 (3): 201-08, 2017.

5- FURTADO R.N.V., RIBEIRO L.H., de ARRUDAABBO B., DESCIO F.J., JUNIOR C.E.M. and SERRUYA D.C.: Nonspecific low back pain in young adults: Associated risk factors. Revista Brasileira de Reumatologia, 54 (5): 371-7, 2014.

6- CÔTÉ P., VAN DER VELDE G., CASSIDY J.D., CARROLL L.J., HOGG-JOHNSON S., HOLM L.W., et al.: The burden and determinants of neck pain in workers. Results of the bone and joint decade 2000-2010 task force on neck pain and its associated disorders. Eur. Spine J., 17: 60-74, 2008.

7- HOGG-JOHNSON S., VAN DER VELDE G., CARROLL L.J., HOLM L.W., CASSIDY J.D., GUZMAN J., et al.: The burden and determinants of neck pain in the general population. Results of the bone and joint decade 20002010 task force on neck pain and its associated disorders. Eur. Spine J., 17: 39-51, 2008.

8- WOLFF R., CLAR C., LERCH C. and KLEIJNEN J.: Epidemiology of chronic non-malignant pain in Germany. Schmerz, 25: 26-44, 2011.

9- CITKO A., GÓRSKI S., MARCINOWICZ L. and GÓRSKA A.: Sedentary Lifestyle and Nonspecific Low Back Pain in Medical Personnel in North-East Poland BioMed Research International, Article ID 1965807; 8 pages, 2018.

10- BOOTH F.W., ROBERTS C.K. and LAYE M.J.: Lack of exercise is a major cause of chronic diseases. ComprehenPhysiol., 2: 1143-211, 2012.

11- BO ANDERSEN L., WEDDERKOPP N. and LEBOEUFYde C.: Association between back pain and physical fitness in adolescents. The Spine Journal, 31 (15): 17404, 2006.

12- BJÖRCK-VAN DIJKEN C., FJELLMAN-WIKLUND A. and HILDINGSSON C.: Low back pain, lifestyle factors and physical activity: A population-based study. Journal of Rehabilitation Medicine, 40 (10): 864-9, 2008.

13- MONTAKARN C. and NUTTIKA N.: Physical activity levels and prevalence of low back pain in Thai call-center operators. Indian J. Occup. Environ Med., 20: 125-8, 2016.

14- SIHAWONG R., JANWANTANAKUL P. and JIAMJARASRANGSI W.: A prospective, cluster randomized controlled trial of exercise program to prevent low back pain in office workers. Eur. Spine J., 23:786-93, 2014.

15- HOFTUN G.B., ROMUNDSTAD P.R. and RYGG M.: Factors associated with adolescent chronic non-specific pain, chronic multisite pain, and chronic pain with high 
disability: the Young-HUNT Study 2008. J. Pain, 13: 87483, 2012.

16- HANNA F., DAAS R.N., EL-SHAREIF T.J., ALMARRIDI H.H., AL-ROJOUB Z.M. and ADEGBOYE O.A.: The Relationship Between Sedentary Behavior, Back Pain, and Psychosocial Correlates Among University Employees. Front Public Health, 7: 80, 2019.

17- FOLEY B., ENGELEN L., GALE J., BAUMAN A. and MACKEY M.: Sedentary behavior and musculoskeletal discomfort are reduced when office workers trial an activity-based work environment. J. Occup. Environ Med., 58: 924-31, 2016.

18- PERRY M.C., STRAKER L.M., ODDY W.H., O'SULLIVAN P.B. and SMITH A.J.: Spinal pain and nutrition in adolescents - an exploratory cross-sectional study. BMC Musculoskelet Disord., 11: 138, 2010.

19- AUVINEN J., TAMMELIN T., TAIMELA S., ZITTING P. and KARPPINEN J.: Associations of physical activity and inactivity with low back pain in adolescents. Scand J. Med. Sci. Sports, 18: 188-94, 2008.

20- World Health Organization: Global Strategy on Diet, Physical Activity and Health. Retrieved from http://www.who.int/dietphysicalactivity/strategy/eb1 1344 /en/index.html, May 2004.

21- CHEN S., LIU M., COOK, BASS S. and LO S.K.: Sedentary lifestyle as a risk factor for low back pain: A systematic review. International Archives of Occupational and Environmental Health, 82 (7): 797-806, 2009.

22- World Health Organization: WHO Director-General's opening remarks at the media briefing on COVID-19. Retrieved from: https://www.who.int/dg/speeches/detail/ who-director-general-s-opening-remarks-at-the-mediabriefing-on-covid-19---11-March-2020, 11 March 2020.

23- Arabic short version of International Physical Activity Questionnaire. Retrieved 15 June 2020, from https://docs.google.com/a/kasralainy.edu.eg/viewer?a=v \&pid=sites\&srcid=ZGVmYXV sdGRvb WFpbnx0aGVp cGFxfGd4OjU 1MzljMzNjMWUyNjQzZQ

24- HAYDEN J.A., VAN TULDER M.W., MALMIVAARA A. and KOES B.W.: Exercise therapy for treatment of non-specific low back pain. Cochrane Database Syst. Rev., 20 (3): CD000335, 2005.

25- HENCHOZ Y. and KAI-LIK SO A.: Exercise and nonspecific low back pain: A literature review. Joint Bone Spine, 75: 533-9, 2008.

26- HENDRICK P., TE WAKE A.M., TIKKISETTY A.S., WULFF L., YAP C. and MILOSAVLJEVIC S.: The effectiveness of walking as an intervention for low back pain: A systematic review. Eur. Spine J., 19: 1613-20, 2010.

27- HENEWEER H., STAES F., AUFDEMKAMPE G., VAN RIJN M. and VANHEES L.: Physical activity and low back pain: A systematic review of recent literature. Eur. Spine J., 20: 826-45, 2011.

28- AINSWORTH B. and YOUMANS C.: Tools for physical activity counseling in medical practice. Obesity, 10: 6975, 2000.

29- PICAVET H.S.J. and SCHUIT A .J.: Physical inactivity: A risk factor for low back pain in the general population? J. Epidemiol. Community Health, 57: 517-8, 2003.

30- Chen S-M., Liu M-F., Cook J., Bass S. and Lo S.K.: Sedentary lifestyle as a risk factor for low back pain: A systematic review. Int. Arch. Occup. Environ Health, 82: 797-806, 2009.

31- GOBBO S., BULLO V., BERGAMO M., DUREGON F., VENDRAMIN B., BATTISTA F., et al.: Physical Exercise Is Confirmed to Reduce Low Back Pain Symptoms in Office Workers: A Systematic Review of the Evidence to Improve Best Practices in the Workplace. Funct. Morphol. Kinesiol, 4 (43), 2019.

32- PUETZ T.W.: Physical activity and feelings of energy and fatigue: Epidemiological evidence. Sports Med., 36 (9): 767-80, 2006.

33- PUETZ T.W., FLOWERS S.S. and O'CONNOR P.J.: A randomized controlled trial of the effect of aerobic exercise training on feelings of energy and fatigue in sedentary young adults with persistent fatigue. Psychother Psychosom, 77 (3): 167-74, 2008.

34- GORDON B. and LUBITZ L.: Promising outcomes of an adolescent chronic fatigue syndrome inpatient programme. J. Paediatr Child Health May, 45 (5): 286-90, 2009.

35- BEACH T.A., PARKINSON R.J., STOTHART J.P. and CALLAGHAN J.P.: Effects of prolonged sitting on the passive flexion stiffness of the in vivo lumbar spine. Spine J., 5: 145-54, 2005.

36- KRAEMER J., HASENBRING M., KRAEMER R. and TAUB E.: Intervertebral Disk Diseases. Causes, Diagnosis, Treatment and Prophylaxis. H. Wilke, Ed.,ThiemeStugart, New York, NY, USA, 1 st edition, 2008.

37- NACHEMSON A.L.: Disc pressure measurements. Spine, 6: 93-7, 1981

38- McGILL S.M., HUGHSON R.L. and PARKS K.: Lumbar erector spinae oxygenation during prolonged contractions: Implications for prolonged work. Ergonomics, 43: 48693, 2000.

39- BRITO R.G., RASMUSSEN L.A. and SLUKA K.A.: Regular physical activity prevents development of chronic muscle pain through modulation of supraspinal opioid and serotonergic mechanisms. Pain Rep., 2 (5): e618, 2017.

40- RAMEL J., BANNURU R., GRIFFITH M. and WANG C.: Exercise for Fibromyalgia Pain: A Meta-Analysis of Randomized Controlled Trials. Current Rheumatology Reviews, 5 (4): 188-93, 2009. 


\section{تأثير جائحة الكوفيد 19 على مستوى نشاط الأفراد وعلاقة ذلك بآلام العمود الفقرى : ماتوى دراسلة على مجموعة من المتطوعين الأصحاء العاء العهري}

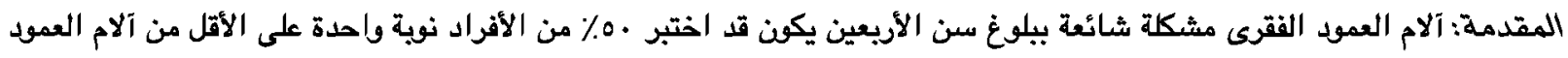

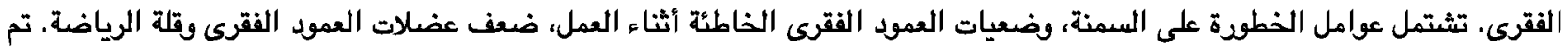

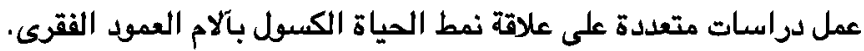

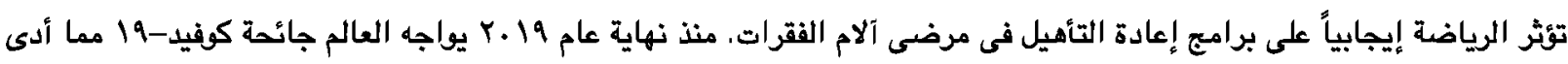

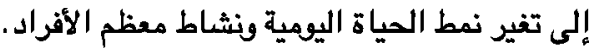

الهدف من البحث: دراسة مدى تغير نمط الحياة الحركية للأفراد بعد جائحة الكوفيد-19 وملاقة ذلك بآلام العمود الفقرى.

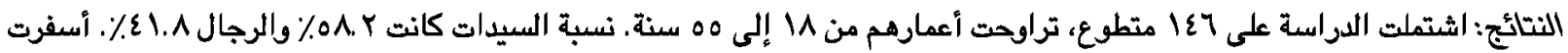

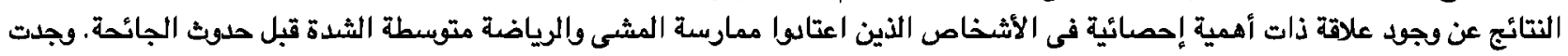

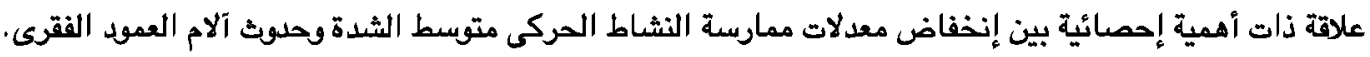

المستخلص: جائحة كوفيد-19 أدت إلى تغير ذو أهمية إحصائية فى ممارسة النثاط الصركى. وجدت علاقة ذات أهمية إحصائية بين

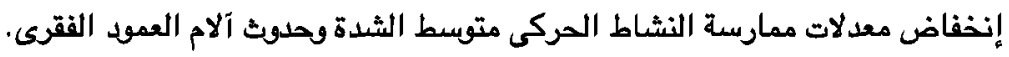

